\title{
Rethinking failure: time for closer engineer-scientist collaborations on design
}

1 Mari R. Tye PhD, CEng, MICE

Project Scientist, NESL, National Center for Atmospheric Research, Boulder, CO, USA

2 Greg J. Holland PhD, FAMS, FAMOS, MAGU

Willis Senior Scientist, NESL, National Center for Atmospheric Research, Boulder, CO, USA
3 James $\mathbf{M}$. Done PhD

Project Scientist, NESL, National Center for Atmospheric Research, Boulder, CO, USA
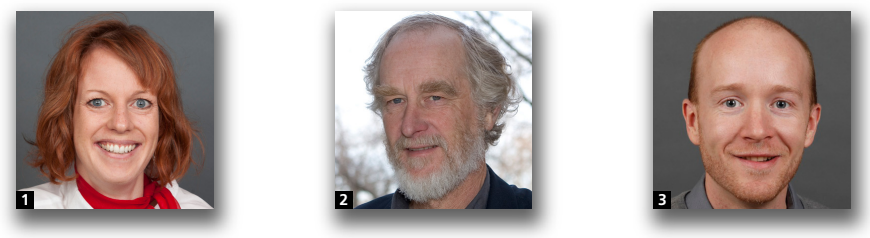

Catastrophic failures in the built and natural environment resulting from climate extremes such as flooding have become all too familiar. Limit state design under changing climate conditions may no longer be appropriate and may lead to more frequent and unplanned failures. Developing optimal design responses by rethinking the target 'failure rate' to reduce our increasing vulnerability to extremes is essential. Addressing this requires strong communication links between the civil engineering community and climate scientists. These communication links, however, have often lacked the essential component of an ongoing two-way interaction promoting clear communication of the core issues. This paper discusses the need for improved dialogue to understand where the built and natural environment is most vulnerable to today's climate extremes and how this vulnerability may develop in the future, and gives examples of successful communication strategies and collaborations between scientists and engineers.

\section{Introduction}

Winter of 2014 was the UK's wettest since the national record began in 1910, resulting in widespread and prolonged flooding across the country; high wind speeds through December and January generated major coastal flooding along the east of the UK and southern England (Met Office, 2014). The unusually severe cold winters of 2009/2010 and 2010/2011 also caused unanticipated damage and disruption arising from the lack of preparation (Defra, 2012). Among other events globally, Hurricane Sandy (in 2012), Typhoon Bopha (in 2012) and flooding in Queensland Australia (in 2011 and 2013) also all demonstrated how sensitive the urban environment is to the impacts from severe weather and the potential global ramifications (Swiss Re, 2014). The resultant catastrophic failures in the built and natural environment from extreme weather phenomena have become all too familiar and suggest that current design approaches and our ability to cope with unusual weather are inadequate (Defra, 2012).
Most engineering solutions are designed within fixed, agreed, design criteria, or using a limit state approach. Once the limit has been exceeded, failure ensues and often catastrophically. Some engineering applications (e.g. communications and power transmission) have long recognised that if failure is inevitable, building redundancy into the design will enable a 'graceful failure' from which the system can recover. Within the context of built infrastructure, designing staged failure can allow partial building collapse and the safe evacuation of any occupants - a standard design requirement in major earthquake zones. A 'graceful failure' design approach to withstand extreme weather events may not only increase resilience but also aid the management of uncertainties surrounding future changes in climate, population growth and urbanisation.

There is growing evidence of increased volatility in hydrological extremes, with both extreme rainfall and droughts becoming more intense and more frequent across the UK 
(Jones et al., 2013a; Slingo et al., 2014) and around the world (e.g. Alexander et al., 2006; Kunkel et al., 2013). There is also substantial evidence for increases in the frequency of the most intense tropical cyclones (e.g. Holland and Bruyère, 2014; Knutson et al., 2013) and in the number and intensity of highlatitude (i.e. over north Europe and the UK) north Atlantic winter cyclones (Met Office, 2014). The recent synthesis report from the IPCC (2013) indicates that the probability of extreme weather is likely to increase over the coming century (Table 1). Increased probability of extreme weather, combined with increasing population in vulnerable regions, heralds worsening climate impacts in the future.

Floods and tropical cyclones are the most frequent and greatest hazards for the largest cities, directly affecting 665 million people worldwide (UN Desa, 2012). In recent years exposure to such events has increased as more people live in vulnerable locations (Swiss Re, 2014) and alter the built and natural environment, increasing the risk posed to urban infrastructure and the likely impacts from extreme weather. The population living within 5 m elevation from mean sea level is expected to double to 400 million by 2100 (Schröder, 2010) which, in combination with sea-level rise, will expose more people to the effects of coastal flooding from tropical cyclones and extratropical wind storms. Yet in the face of an uncertain climate, design approaches for engineered systems have remained largely static. Indeed, engineered systems to mitigate or control the consequences of extreme weather have been developed empirically from historical observations and largely ignore recent and potential future changes in frequency or intensity.

The impacts of weather-related hazards (such as drought, flood, tropical cyclones and extratropical wind storms) arise from complex interactions in the human and natural environments between exposure to the hazard and relative sensitivity, or vulnerability, to the impact. Interactions within the built environment and diverse vulnerabilities can lead to a domino effect of failure. For instance, multiple-basin flooding transcends national and international boundaries, and associated poor communication may lead to failures in system resilience, emergency response and rebuild efforts. An example is the devastation witnessed in Pakistan and northern India in 2010.

Developing optimal responses to the anticipated changes in extreme weather patterns, and to our increasing vulnerability and exposure, is essential. In a changing climate, how can engineers ensure that their design will last and still be effective for the intended life of the structure? Three key themes of communication, managing uncertainty and the concept of graceful failure are used to frame the discussion on how to develop resilience to current and future climate extremes and socio-economic pressures.

There is a wealth of scientific knowledge, such as the IPCC AR5 (IPCC, 2013) and region- or discipline-specific assessment reports (e.g. Murphy et al., 2009), but these are not always useful or directly usable. For example, lack of a structured two-way dialogue between engineers and scientists may lead to the production of highly detailed data sets that do not answer the essential requirements of engineering design. Stagnation in the communication process can also be aggravated by the many sources of uncertainty in climate predictions, including model construction, emissions scenarios and the chaotic non-linear behaviour of the climate (Slingo and Palmer, 2011). The Institution of Civil Engineers first came into being to promote the exchange of knowledge and ideas, with the consequence that the accumulated knowledge has helped to inform planning and policy decisions. With the potentially large changes and uncertainty surrounding the future climate and, in particular, weather-related extremes, the need to improve dialogue between engineers, policy makers and scientists has only increased.

Sustained dialogue between scientists across multiple disciplines and practitioners, such as engineers and policy makers, is key to ensuring the output from future climate science research meets societal needs. Dilling and Lemos (2011) found that 'nearly every case of successful use of climate knowledge involved some kind of iteration between knowledge producers and users'. Iteration between the development of climate

Description of anticipated changes in extreme weather

Frequency of extreme precipitation very likely to increase; monsoonal systems will likely shift later in the annual cycle.

Droughts are likely to intensify in arid regions such as north central America.

Frequency, duration and intensity of heat waves are virtually certain to increase.

Intensity of tropical and extra-tropical cyclones is expected to increase.

Frequency of most intense tropical cyclones will more likely than not increase in the north Atlantic and western north Pacific.

Sea-level rise of $0.52-0.98 \mathrm{~m}$ (relative to 1986-2005) is very likely to contribute to extreme sea levels and associated flooding.

Table 1. Anticipated changes in extreme weather over the twenty-

first century (IPCC, 2013) 
information and its use will help realise the full societal value of climate science. Such iteration should be robust to climate prediction uncertainty and incorporate the knowledge of this uncertainty directly into decision making. The political response to flooding on the Somerset Levels over January and February 2014 is an example of where a lack of timely communication with appropriate experts can lead to poor decision making with potentially detrimental consequences (Bates, 2014). As Bates (2014) observed, disasters should prompt disaster management; planning decisions for resilience to high-impact weather should be made at leisure when there is time to gather and consider evidence.

Engineered systems that are resilient to the hazards posed by high-impact weather, their increasing probability and our increasing exposure, thus require a fully integrated approach to design. In this context, 'resilience' refers to the ability to recover to an operable state after a disaster (Tye, Changes in extreme precipitation and the need for resilience, unpublished). Figure 1 illustrates that optimal decisions for resilience are achieved from a discussion between information producers (scientists and engineers) and users (e.g. policy makers). Those who are directly vulnerable to weather extremes are often not

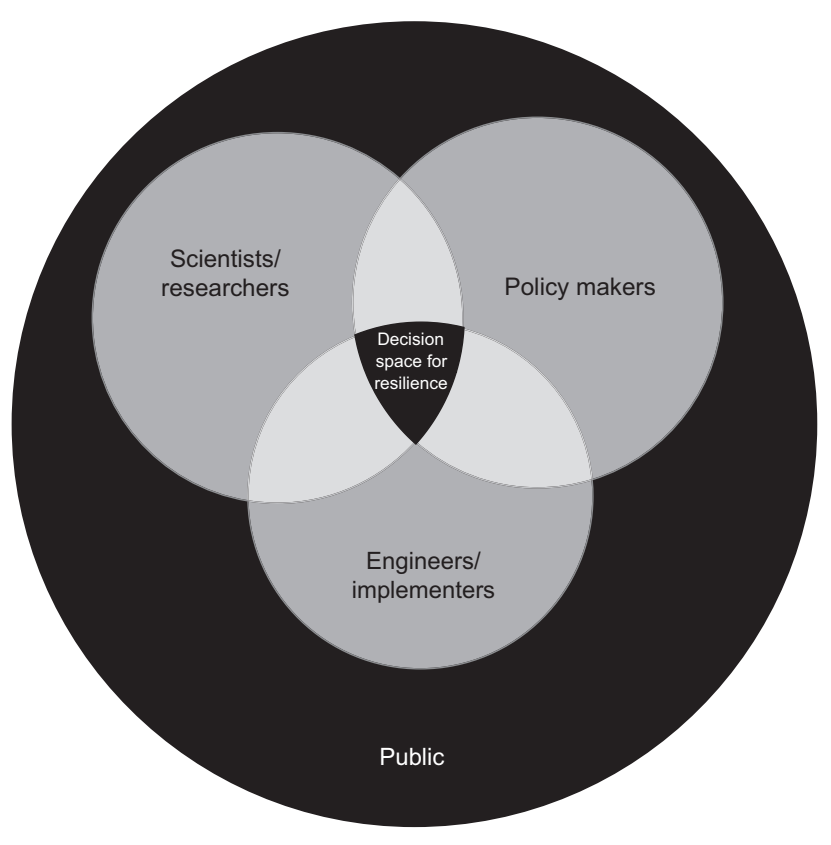

Figure 1. Co-production of information to achieve resilient decisions for risk management is achieved through integrating the diverse requirements and constraints of different groups, including affected end users. 'Public' is used here to signify those directly and indirectly affected, but not included in the production of the solution fully engaged in this decision making, resulting in the loss of valuable local knowledge and reducing the effective implementation of any solution (Preston et al., 2014). Resilient adaptation solutions benefit most from involvement of all sectors, scientists, engineers, policy makers and end users.

Engineers have always designed with uncertain knowledge, from ground conditions and projected population growth, to the weather during construction and the cost of materials. Potential future changes in extreme weather can be viewed as another component of total uncertainty. In some instances the uncertainty surrounding changes in extreme weather may be small compared with other sources of uncertainty (e.g. population changes) or incorporated within design factors of safety.

Figure 2 compares the cascade of uncertainty that develops from a 'top-down' approach with that obtained when only the most critical impacts are examined. It is not possible to remove all uncertainty, but the second approach has the capacity to make the problem more manageable and lead to more resilient design solutions.

Resilient responses to extreme weather accept a level of uncertainty about the magnitude of the impact and embed redundancy in protection levels through a tiered response. However, flood defence solutions often identify a target event probability and design to withstand up to this event with some freeboard allowance. Designing 'fail-safe' options may lead to higher consequences in the event of failure - for example, structural or overtopping - as the risks may not have been fully perceived or understood by those in danger. Focusing on a single engineered solution may also lead to multiple failures if responsibilities between agencies or interfaces with other systems have not been clearly defined.

Robustness and resilience can be achieved by adopting a 'graceful failure' approach that clearly acknowledges realistic protection levels, includes a portfolio of options, such as land management and controlling urban sprawl, and includes more effective contingency planning. Such an approach automatically accounts for uncertainty in the future climate and embeds resilience in adaptation planning.

\section{State of the science}

Societal factors may explain a large component of the recent upswing in natural hazard losses (Mohleji and Pielke, 2014) and future societal changes will continue to drive increases in losses. But these losses will be enhanced by simultaneous increases in weather- and climate-related hazards (Fowler and Wilby, 2010; Holland and Bruyère, 2014; IPCC, 2013). Thus, the combined societal and weather changes will compound the impacts and lead to more damaging events in the future (Morss et al., 2011). 


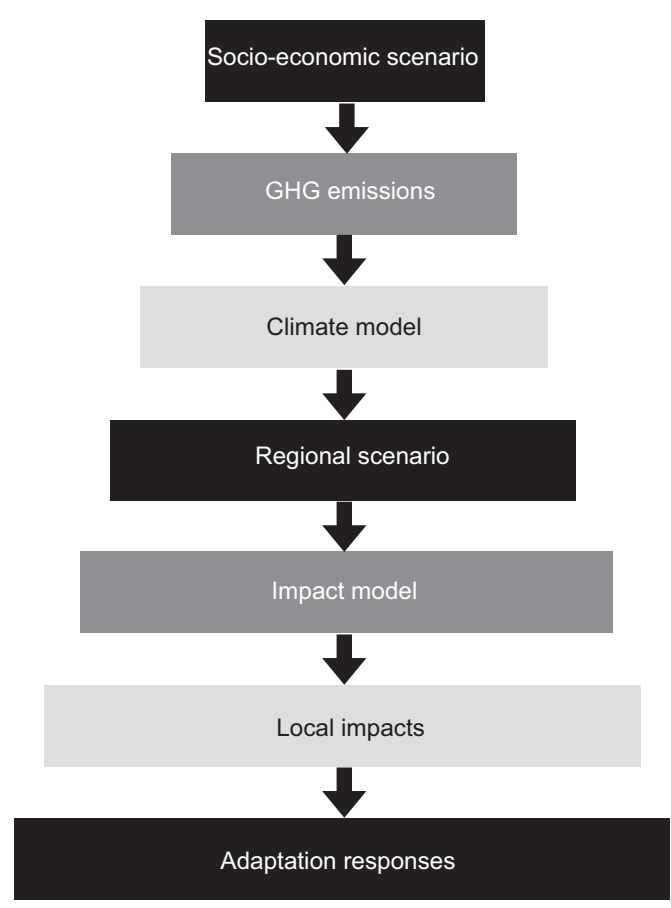

(a)

Figure 2. (a) Cascade of uncertainty that develops from a 'topdown' approach, starting from possible population growth.

(b) Reducing the cascade of uncertainty by focusing design and decision making on the critical components of a system that are

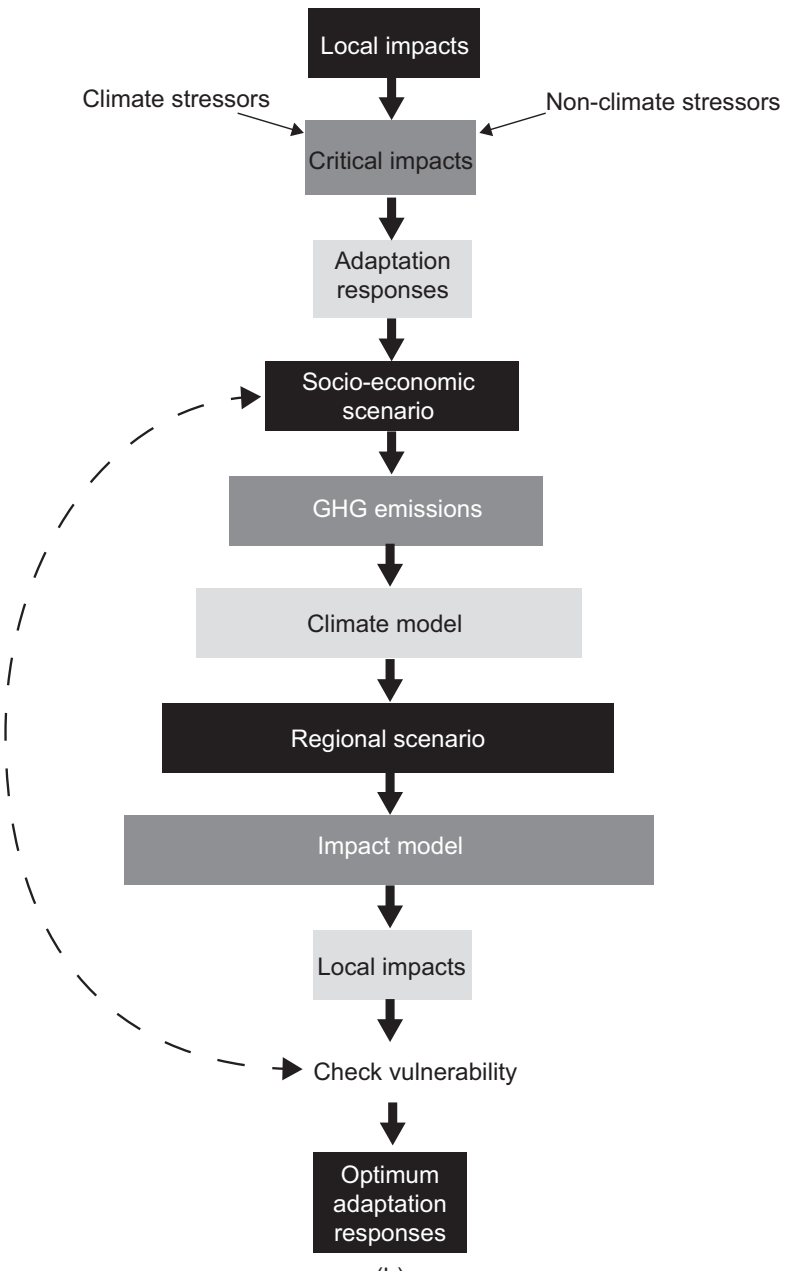

(b)

vulnerable to high-impact weather. The width of the bars indicates the relative size of the uncertainty (adapted from Wilby and Dessai (2010), Figure 1)

may make current practices based on empirical past evidence ineffective. For society to confront this new era of catastrophes, the provision and use of climate information needs to incorporate new advances in predictability capacity.

Decades of public investment have supported the development of leading climate models. Recent years have seen significant advances in full dynamical models of the climate system improving near-term projections to assist decision making. These advances in climate science herald a new era for our understanding, prediction and management of climate impacts. The use of global climate projections is becoming commonplace in long-range planning fields such as water resources and infrastructure design, yet there lies a mismatch between the spatial and temporal scales of credible climate information and
Future climate variability and change brings the possibility of high-impact events outside the range of our experience that 
High confidence of increases in extreme precipitation intensity and frequency with some regional and seasonal differences. This will lead to increased probability of pluvial and groundwater flooding and sustained high river flows.

High confidence of increases in drought frequency in arid regions, medium confidence elsewhere. This will lead to increases in subsidence, foundation failure and movement/cracking in buried pipes.

High confidence of frequency and intensity of heat waves. This will lead to failures in temperature-sensitive infrastructure (tarmac, rail tracks, and so on) and overloaded electrical infrastructure due to increased demands for cooling.

Low confidence of increases in surface wind speeds, gusts and duration in high latitudes, with possible increase in wind loading and wind-borne rain damage.

High confidence that depth of seasonally frozen ground has reduced, leading to increased freeze-thaw damage in non-permafrost regions.

Table 2. Observed changes in extremes and the associated inferred consequences (adapted from IPCC (2013))

that required for design. Although climate scientists are increasingly engaged in assessing the societal value of climate science, rather than just improving it, there remains substantial need for increased engagement with those using the science. Meehl et al. (2009), for example, suggest the value of climate predictions should be quantified in terms of social and economic value. This integration of climate science with decision-making needs is a critical requirement to ensure that climate science is relevant to societal requirements and that predictive capabilities are fully utilised.

Despite advances in climate predictions, the predictions of extreme weather phenomena remain inadequate for local decision-making and design purposes. The technique to align the scale of climate predictions with the decision scale is known as downscaling, and can be grouped into dynamical or statistical downscaling, or a hybrid combination of the two (Tye, Changes in extreme precipitation and the need for resilience, unpublished) for more information. Combinations of dynamical and statistical techniques to assist with decision making and design (e.g. Guyennon et al., 2013) are showing promise in characterising spatial changes and developing weather scenarios that are useful for impact assessments. However, there is a concern that downscaling may raise more questions than it resolves (Hewitson et al., 2013). For example, the choice of a future anthropogenic emissions scenario and plausible range of climate predictions can substantially affect the downscaling result. The solution is to adopt an iterative process, as illustrated by Figure 2(b), starting from the systems that are most vulnerable to current impacts. Again, this requires full dialogue between scientists, engineers, policy makers and end users.

A tool that is widely used by the insurance industry to identify and quantify climate risk is the catastrophe (CAT) model. CAT models have become fundamental for risk assessment and management (Grossi et al., 2005) and were developed to address the need for local-scale risk information. The four main components are hazard, exposure, vulnerability and loss. First, the CAT model defines the hazard phenomenon (e.g. flood) and generates a hazard event set. Each hazard event is defined by a specific magnitude, size or location and is assigned a probability of occurrence. Second, the model characterises the exposure of infrastructure at risk using construction and occupancy types, building height, age and design codes and assigns a geographic location. Third, the vulnerability to the exposure is quantified, based on physical relationships between a characteristic or combination of characteristics of the hazard and damage. Finally, the expected loss is calculated, based on direct losses including the cost to repair and/or replace a structure, and indirect losses including business interruption and relocation costs. Together, the hazard event set, exposure and vulnerability components yield a probabilistic impact risk analysis.

Traditional CAT modelling has relied on sampling from probability distributions fitted to historical hazard data. Given the non-stationarity of the climate, this presents a serious limitation since it cannot account for the evolution of risk in the past or how it may change in the future. In contrast, full dynamical and physical models of weather and climate can provide: physically based responses to climate variability and change; events outside the range of the historical record; and information on dependency between hazards (e.g. simultaneous highest astronomical tide and sea surge, or several extreme events in succession). These also have their limitations, chief among which are the expense of making detailed simulations relevant to specific extremes and regional vulnerabilities. Risk assessments that incorporate a hybrid combination of climate predictions and statistical approaches are an exciting and important development for decision making and uncertainty assessments relevant to future impacts. 


\section{Developing a dialogue}

A recent workshop at the National Center for Atmospheric Research, USA, brought together climate scientists, civil engineering practitioners and governmental departments to discuss how scientific and engineering approaches to weather and climate extremes should be transformed to reduce societal vulnerability (Jones et al., 2013b). Gaps in information quickly became apparent, together with the inadequate use of climate and engineering information, by either profession, and a lack of standardised best practice. A major finding was the need to reframe approaches to applying scientific and engineering knowledge to underpin the planning process. Rather than transferring climate information from the information developer to the information user, an ongoing and engaged dialogue is essential to integrate climate information and uncertainty effectively in planning and design. As noted by Gersonius et al. (2012), meaningful dialogue with decision makers and end users to identify their acceptable level of risks or system constraints is a critical part of this process.

Initial steps by the authors to integrate predictions of weather/ climate extremes with societal decision making have indicated that there is considerable potential to reduce future impacts at minimal current cost (Czajkowski and Done, 2014; Done et al., 2013). This view is supported by successful collaborations with the insurance and offshore engineering sectors to determine the current and future financial implications of extreme weather.

The Willis Research Network, sponsored by Willis, a global insurance broker, was formed in 2006 to integrate science, insurance and resilience. The Network is a successful example of sustained dialogue between scientists and decision makers aligning research with the needs of industry while supporting leading-edge interdisciplinary public science. The key achievement has been funded and dedicated time for two-way dialogue in the form of face-to-face meetings and longer-term visits between research institutions and industry.

Similar collaboration is promoted by other major insurance and reinsurance groups, who also advocate learning from recent disasters to enhance current resilience (Zurich Insurance Group, 2013). Among the most important actions identified are improved communication of the risk, and forging alliances between insurers, government and civil society to achieve and maintain resilience. A common theme raised by insurance groups is that physical prevention mechanisms for extreme weather are important, but have a finite limit beyond which catastrophes will occur. Full resilience to extreme weather is only possible with the financial ability to support emergency relief, post-disaster recovery and reconstruction (Swiss Re, 2014). Financial organisations are also well placed to influence practicable changes to land-use policy; a direct consequence of previous financial intervention led to zero loss of life during the recent UK flooding (Slingo et al., 2014). However, such interventions need to be carefully managed and the associated risks communicated effectively, to avoid increased urbanisation in the defended at-risk areas (Montgomery et al., 2012).

Another example of sustained dialogue between scientists, engineers and decision makers is the Research Partnership to Secure Energy for America, under the US Department of Energy, that supports direct collaborative projects between scientists and engineers within the offshore energy industry. According to recent assessments, the proportion of intense hurricanes has increased substantially and is likely to increase further. This has far-reaching implications for the offshore energy industry as it raises the possibility that new coastal and offshore facilities may be under-designed, and that older facilities may need hardening in order to maintain presently accepted risk levels. Yet over-reaction may also cause considerable unwarranted costs. This collaborative research is targeted to the needs of engineering designers to mitigate the costs of future hurricane activity. As with the Willis Research Network, success is being achieved through ongoing two-way dialogues between the researchers and engineers in the participating energy companies.

Outside these highly focused collaborations, greater use needs to be made of bridging organisations who can facilitate meaningful discussions by assisting with the communication of risk, uncertainty and user needs. Chatham House (www.chatham house.org) is one such independent institute, the focus of which is neither solely on the science nor on the decision process, that analyses and summarises current research to support decision makers and policy makers. Chatham House regularly hosts symposia and conferences to bring together diverse audiences to develop workable solutions to critical challenges. Recent conferences have focused primarily on climate change mitigation. However, the established framework could support discussions between decision makers, engineers and information suppliers to determine appropriate measures for resilience to extreme weather. Similar organisations exist worldwide, such as the Risk Management and Decision Process Center at the Wharton School of the University of Pennsylvania (www. wharton.upenn.edu/riskcenter/). With a primary focus on economics and decision sciences, and working with decision makers, the Center identifies ways that governance can improve risk-related decision making.

\section{Improving resilience through synergy}

Catastrophic events often trigger a review of the status quo, if not a policy change (Linham and Nicholls, 2012). An example of a positive and deliberated response is that of New York City, USA. Prompted by other 'near-miss' events, such as Hurricane Irene (in 2011), a multi-disciplinary team started to consider coastal adaptation measures and to identify critical infrastruc- 
ture networks with the assistance of stakeholders from public and private organisations. This remained a theoretical exercise until October 2012. Rebuilding the city to improve the resilience of areas that were unaffected by Hurricane Sandy and to reduce the vulnerability in affected areas is part of an integrated and ongoing decision that has been fully informed by users, decision makers and scientists.

Ongoing decision making that is informed by current risks and impacts naturally leads to the development of flexible adaptation plans that will be resilient to weather extremes both now and in the future. Revisiting adaptation plans at regular intervals ensures that the resilience is maintained under future climate conditions. Importantly, adopting a design that embeds graceful failure allows for uncertainty surrounding the future and incorporates flexibility in the design. This is illustrated in Figure 3 where the proportional responses to high-impact weather can be categorised as 'resilient', 'coping' and 'failing'. Resilient design results in no loss of life, minimises damage and achieves swift recovery to an operable state after the event. Coping with the hazard indicates that while damages occur, they are not catastrophic; however, the recovery process may be prolonged. Failure indicates that catastrophic losses can occur, including loss of life, and the extended or permanent displacement of people from their homes and businesses; recovery to a stable state may take years. The examples in Section 3 suggest that ensuring a full dialogue between engineers, users and scientists, and utilising flexible design principles, can reduce designs that fail or merely cope in the future. For example, rather than considering flood defence as one option of either protection, accommodation of minor incursions, or retreat from the hazard (Linham and Nicholls, 2012), the authors advocate a move toward graceful failure encompassing tiered levels of protection, incursion and retreat.
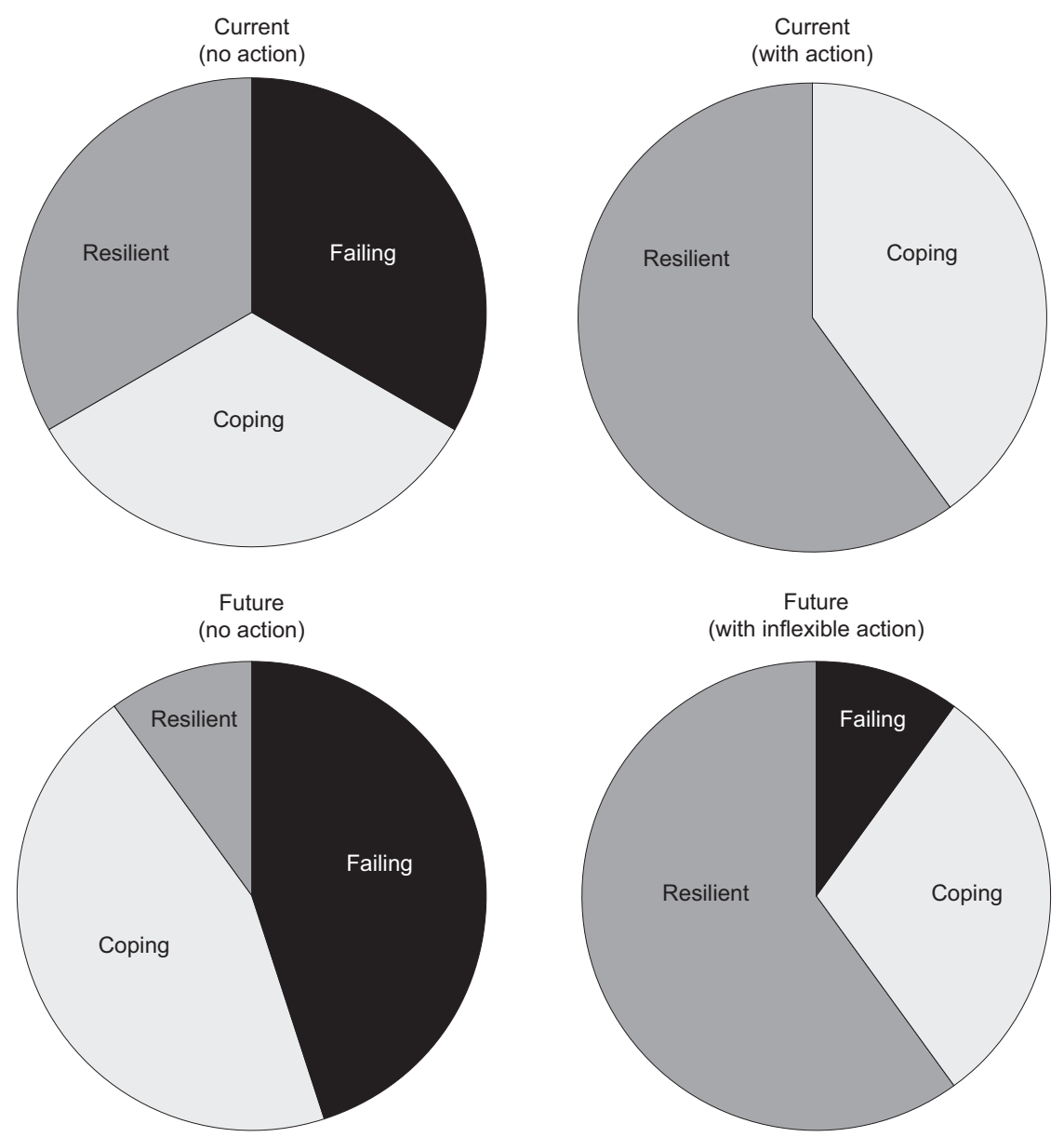

Figure 3. The relative ability to withstand the effects of highimpact weather 


\section{Summary}

A recurring theme through this paper has been the benefits arising from greater collaboration and dialogue between the users and producers of information on climate and weather extremes. Particular emphasis was placed on integrating topdown and bottom-up decision-making processes. This is best served by developing interactions at the early research and design stages so that the user needs are implicit in the research. A focus should be on the infrastructure elements and those societal groups that are most vulnerable to extreme weather and likely to suffer secondary, or even tertiary, consequences as a result of unplanned failure. Successful examples of the application of integrated research and design in the insurance/ reinsurance and offshore energy industries were provided.

An effective method to achieve two-way dialogue and develop realistic solutions is to identify the possible sources of vulnerability and risk that are experienced today and to focus only on those that are critical or have secondary impacts. Relying on a single engineered solution to the hazard can lead to catastrophic failure, particularly where responsibilities between agencies and interfaces with other systems have not been clearly defined. A 'graceful failure' approach to engineering solutions is recommended, one that encompasses a portfolio of options and includes improved contingency planning, embeds resilience within the adaptation solution and accounts for uncertainty in the future climate.

\section{Acknowledgements}

The National Center for Atmospheric Research is sponsored by the National Science Foundation (NSF). This work was partially supported by NSF EASM grant S1048841, the Willis Research Network and the Research Partnership to Secure Energy for America.

\section{REFERENCES}

Alexander LV, Zhang X, Peterson T et al. (2006) Global observed changes in daily climate extremes of temperature and precipitation. Journal of Geophysical Research 111, D05109, http://dx.doi.org/10.1029/2005JD006290.

Bates $\mathrm{P}$ (2014) Flood crisis: dredging is a simplistic response to a complex problem. The Guardian. See http://www. theguardian.com/environment/2014/feb/12/flood-crisisdredging-climate-change (accessed 10/03/2014).

Czajkowski J and Done J (2014) As the wind blows? Understanding hurricane damages at the local level through a case study analysis. Weather, Climate, and Society 6(2): 238-252.

Defra (Department for Environment, Food and Rural Affairs) (2012) The UK Climate Change Risk Assessment 2012 Evidence Report. Defra, London, UK.

Dilling L and Lemos MC (2011) Creating usable science: opportunities and constraints for climate knowledge use and their implications for science policy. Global Environmental Change 21(2): 680-689.

Done JM, Holland GJ, Bruyère $\mathrm{CL}$, Leung $\mathrm{LR}$ and Suzuki-Parker A (2012) Modeling high-impact weather and climate: lessons from a tropical cyclone perspective. Climatic Change 129(3-4): 381-395, http://dx.doi.org/10.1007/ s10584-013-0954-6.

Fowler HJ and Wilby RL (2010) Detecting changes in seasonal precipitation extremes using regional climate model projections: implications for managing fluvial flood risk. Water Resources Research 46(3): W03525, http:// dx.doi.org/10.1029/2008WR007636.

Gersonius B, Ashley R, Pathirana A and Zevenbergen C (2012) Adaptation of flood risk infrastructure to climate resilience. Proceedings of the Institution of Civil Engineers Civil Engineering 165(6): 40-45, http://dx.doi.org/10.1680/ cien.11.00053.

Grossi P, Kunreuther $\mathrm{H}$ and Patel CC (2005) Catastrophe Modeling: A New Approach to Managing Risk, Volume 25. Springer, Boston, MA, USA.

Guyennon N, Romno E, Portoghese I et al. (2013) Benefits from using combined dynamical-statistical downscaling approaches - lessons from a case study in the Mediterranean region. Hydrology and Earth System Sciences 17(2): 705-720.

Hewitson BC, Daron J, Crane RG, Zermoglio MF and Jack C (2013) Interrogating empirical-statistical downscaling. Climatic Change 122(4): 539-554.

Holland GJ (2008) A revised hurricane pressure-wind model. Monthly Weather Review 136(9): 3432-3445, http://dx.doi. org/10.1175/2008MWR2395.1.

Holland G and Bruyère CL (2014) Recent intense hurricane response to global climate change. Climate Dynamics 42(3-4): 617-627, http://dx.doi.org/10.1007/s00382-0131713-0.

IPCC (Intergovernmental Panel on Climate Change) (2013) Climate Change 2013: The Physical Science Basis. Contribution of Working Group I to the Fifth Assessment Report of the Intergovernmental Panel on Climate Change (Stocker TF, Qin D, Plattner G-K (eds)). Cambridge University Press, Cambridge, UK.

Jones MR, Fowler HJ, Kilsby CG and Blenkinsop S (2013a) An assessment of changes in seasonal and annual extreme rainfall in the UK between 1961 and 2009. International Journal of Climatology 33(5): 1178-1194.

Jones MR, Holland GJ and Done JM (2013b) Integrating science and engineering to reduce vulnerability to climate extremes. Eos, Transactions American Geophysical Union 94(49): 474.

Knutson TR, Sirutis J, Vecchi G et al. (2013) Dynamical downscaling projections of twenty-first-century Atlantic hurricane activity: CMIP3 and CMIP5 model-based scenarios. Journal of Climate 26(17): 6591-6617. 
Kunkel KE, Karl T, Brooks $\mathrm{H}$ et al. (2013) Monitoring and understanding trends in extreme storms: state of knowledge. Bulletin of the American Meteorological Society 94(4): 499-514.

Linham MM and Nicholls RJ (2012) Adaptation technologies for coastal erosion and flooding: a review. Proceedings of the Institution of Civil Engineers - Maritime Engineering 165(3): 95-111.

Meehl GA, Goddard L, Murphy J et al. (2009) Decadal prediction. Bulletin of the American Meteorological Society 90(10): 1467-1485.

Met Office (2014) Wettest Winter for England and Wales Since 1766. Met Office, London, UK. See http://www.metoffice. gov.uk/news/releases/archive/2014/early-winter-stats?utm_ source $=$ UKCIP+enews\&utm_campaign $=$ a947142bca03_UKCIP_news_March_20143_7_2014\&utm_ medium $=$ email\&utm_term $=0 \_$a7d6f30eab-a947142bca3622621 (accessed 13/03/2014).

Mohleji S and Pielke R (2014) Reconciliation of trends in global and regional economic losses from weather events: 1980 2008. Natural Hazards Review 15(4): 04014009, http://dx. doi.org/10.1061/(ASCE)NH.1527-6996.0000141.

Montgomery M, Broyd T, Cornell S et al. (2012) An innovative approach for improving infrastructure resilience. Proceedings of the Institution of Civil Engineers - Civil Engineering 165(6): 27-32, http://dx.doi.org/10.1680/cien.11.00062.

Morss RE, Wilhelmi O, Meehl G and Dilling L (2011) Improving societal outcomes of extreme weather in a changing climate: an integrated perspective. Annual Review of Environment and Resources 36(1): 1-25.
Murphy J, Sexton D, Jenkins G et al. (2009) Climate Change Projections. Met Office Hadley Centre, Exeter, UK.

Preston I, Banks N, Hargreaves K et al. (2014) Climate Change and Social Justice: An Evidence Review. Joseph Rowntree Foundation, London, UK.

Schröder T (ed.) (2010) World Ocean Review: Living with the Oceans. Maribus GmbH, Hamburg, Germany. See http:// worldoceanreview.com/en/ (accessed 13/03/2014).

Slingo J and Palmer T (2011) Uncertainty in weather and climate prediction. Philosophical Transactions. Series A: Mathematical, Physical, and Engineering Sciences 369(1956): 4751-4767.

Slingo J, Belcher S, Scaife A et al. (2014) The Recent Storms and Floods in the UK. Met Office, UK. See http://www. metoffice.gov.uk/media/pdf/g/e/Recent_Storms_Briefing_ Final_SLR_20140210.pdf (accessed 19/03/2014).

Swiss Re (2014) Natural Catastrophes and Man-made Disasters in 2013. Swiss Re, Zurich, Switzerland. See http://media.swissre. com/documents/sigma1_2014_en.pdf (accessed 27/03/2014).

UN Desa (United Nations Department of Economic and Social Affairs Population Division) (2012) World Urbanization Prospects: The 2011 Revision. UN Desa, New York, NJ, USA. See http://esa.un.org/unup/pdf/WUP2011_Highlights. pdf (accessed 13/03/2014).

Wilby RL and Dessai S (2010) Robust adaptation to climate change. Weather 65(7): 180-185.

Zurich Insurance Group (2013) European Floods: Using Lessons Learned to Reduce Risks. Zurich Insurance Group, Zurich, Switzerland.

\section{WHAT DO YOU THINK?}

To discuss this paper, please email up to 500 words to the editor at journals@ice.org.uk. Your contribution will be forwarded to the author(s) for a reply and, if considered appropriate by the editorial panel, will be published as discussion in a future issue of the journal.

Proceedings journals rely entirely on contributions sent in by civil engineering professionals, academics and students. Papers should be 2000-5000 words long (briefing papers should be 1000-2000 words long), with adequate illustrations and references. You can submit your paper online via www.icevirtuallibrary.com/content/journals, where you will also find detailed author guidelines. 